\title{
Abissalidades a contrapelo: o palhaço do circo sem futuro ${ }^{1}$
}

\section{DANIEL PELLEGRIM SANCHEZ LUDMILA DE LIMA BRANDÃO}

\section{Resumo}

Articulando-se à ideia de Boaventura de Sousa Santos de que o pensamento moderno ocidental é abissal, exploramos o funcionamento dessas "abissalidades", as quais hierarquizam e invisibilizam saberes e práticas, e que operam a transmutação da antiga dominação colonial (ou colonialismo) em colonialidade, no sistema das artes visuais.

Palavras-chave: Artes visuais, pensamento abissal, colonialidade Identificamos, então, assim como na "colonialidade do saber", estes mesmos dispositivos: as divisões na realidade da produção artística sob uma perspectiva abissal. 


\title{
Abyssalities against the grain: the clown circus without a future
}

\section{LUDMILA DE LIMA BRANDÃO \\ DANIEL PELLEGRIM SANCHEZ}

\begin{abstract}
By articulating Boaventura de Sousa Santos' notion that the Western modern thinking is an abyssal thinking, we examine the functioning of such "abyssalities", which hierarchize and turn knowledge and practices invisible, as well as operate the transmutation of old colonial domination (or colonialism) into coloniality in the visual arts system. Then we identify - as in the "coloniality of knowledge" these same devices: the divisions in the reality of artistic production under an abyssal perspective.
\end{abstract}

Keywords:

Visual arts, abyssal thinking, coloniality 


\title{
Abismalidades a contrapelo: el payaso del circo sin futuro
}

\author{
LUDMILA DE LIMA BRANDÃO \\ DANIEL PELLEGRIM SANCHEZ
}

\section{Resumen}

Fundamentados en la idea de Boaventura de Sousa Santos que defiende que el pensamiento moderno occidental es un pensamiento abismal, exploramos el funcionamiento de esas abismalidades que jerarquizan e invisibilizan otros saberes y prácticas que contribuyen a la transmutación de la antigua dominación colonial llamada colonialismo en la colonialidad. $\mathrm{Al}$ igual que la colonialidad del saber, identificamos en el sistemas de las artes visuales dispositivos de colonialidad, es decir, segmentaciones de la realidad de la producción artística bajo una perspectiva abismal que asimismo pondera sólo a

Palabras clave: Artes visuales, pensamiento abismal, colonialidad algunos artistas y obras. De ese modo identificamos, en este artículo, algunos de los dispositivos coloniales que continúan estableciendo escalafones en el sistema de las artes visuales. 


\section{Das abissalidades e amarrações Terra-Sol}

Quando se ouve a palavra "abissal", via de regra, logo a associamos a vários tipos de abismo, a exemplo das depressões ou falhas geológicas proporcionadas por diferentes relevos em uma paisagem (serras, vales, montanhas etc.), contudo, o termo é também usado para cavernas verticais e regiões marítimas com grande profundidade. Diferentemente dos relevos vistos nas paisagens da superfície terrestre, que durante o dia ficam bem iluminados, na zona abissal marítima ou abisso-pelágica, como também nas profundezas das cavernas verticais (subsuperficiais), dominam as trevas, sem o benefício da luz do sol que aí não consegue penetrar. Por essa especificidade da ausência de luz, nessas regiões encontram-se seres vivos muito particulares, adaptados a um ecossistema próprio, o qual dispensa a luz. Porém, abaixo da zona abissal, localiza-se a zona "hadal", palavra que em francês significa "lugar da morte": uma referência ao deus Hades da mitologia grega, também conhecida como fossa oceânica² .

Segundo uma lógica oceanográfica, essas divisões são feitas com base na profundidade, que nessas regiões podem chegar a mais de $11 \mathrm{~km}$, com uma pressão que pode atingir 11000 psi.

O gráfico a seguir segue padrões cartesianos, ou seja, as linhas nele traçadas classificam diferentes áreas ou regiões marítimas, arbitrando fronteiras e espaços com nomes que seguem quantificações de penetração da luz do sol, da profundidade e do tipo de vida marinha (epi, meso, bati, abisso, ou hado). Na perspectiva imagética a seguir, o sol e o mar permanecem estáticos (amarrados à imagem) em suas posições polarizadas, tendo no sol o fundamento, o ponto zero, no alto do gráfico. Ao escolher o sol para o alto da imagem (uma escolha evidentemente arbitrá- 


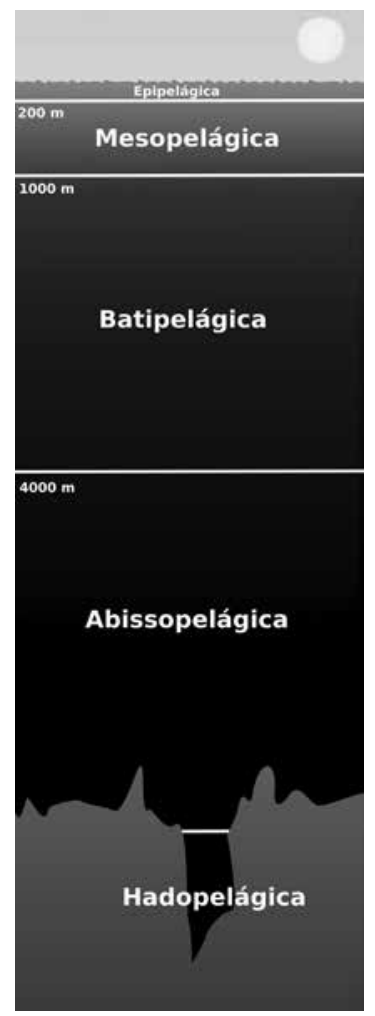

Figura 1

Camadas da zona pelágica. Autor: $\mathrm{Capmo}^{3}$

Figura 2

Melanocetus johnsonii ou peixe-diabo negro.

Foto: Sven Tränkner/Senckenberg Forschungsinstitut und Naturmuseum $^{9}$. ria), a lua é claramente elidida do sistema: há sempre (e somente) luz acima do mar. Por sua vez, ao ignorar a dinâmica da rotação ou do giro do planeta Terra em relação ao sol, o gráfico cristaliza um dégradé, uma hierarquia vertical de luz que vai da zona totalmente iluminada, no topo, à escuridão absoluta na base.

Essa construção, que alimenta muitos imaginários, é arrematada com a escolha de Hades, o deus dos mortos, do mundo inferior na mitologia grega, para denominação dessas zonas interiores (do mar, da terra), onde a vida se desenvolve em condições consideradas hostis para o ser humano4.

Em que pese a evidente importância dos estudos oceanográficos, não podemos deixar de identificar, nessa construção gráfica, uma semiosfera ${ }^{5}$ com aspectos hierárquicos que nos remete ao machismo na ocultação da lua e ao racismo, ao subalternizar o escuro. É possível perceber também o caráter antropocêntrico da ancoragem gráfica. A semiosfera ganha densidade com a designação dos seres abissais, impotentes diante dos dispositivos humanos, como o pequeno peixe-diabo negro ${ }^{6}$ (Fig. 2), cujo nome evidencia estereótipos. Tais enunciados, que funcionam de forma espetacular, criam um ilusionismo cercado de representações e evocações preconceituosas que, por outro lado, lança na invisibilidade os modos singulares dessas vidas, a biodiversidade, a complexidade ecossistêmica dessas outras regiões, constituindo e reforçando uma abissofobia $^{7}$ no mundo troposférico ${ }^{8}$. Contudo, o medo do que se considera hostil, o medo da profundidade, da ausência de luz, de ser implodido nas diferenças extremas de pressão, não são suficientes para frear o arrivismo ocidental-capitalista e sua gigantesca máquina de exploração. Para a exploração das zonas hadais, inventou-se o curioso submersível de nome "batiscafo".

O termo abismo também é usado como metáfora para a depressão psicológica ("fundo do poço") ou para os extremos rela-

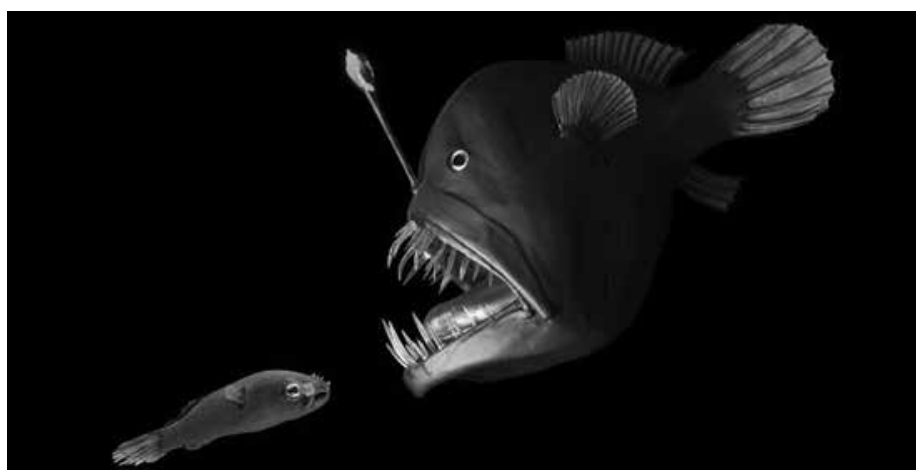


tivos às diferenças ("há um abismo entre nós"). Neste sentido, Santos (2010, p. 31) fala que o "pensamento moderno ocidental é um pensamento abissal". Ele afirma que a modernidade é um sistema que produz distinções visíveis e invisíveis; um sistema formado por linhas radicais que dividem a realidade social em dois universos distintos: o universo "deste lado da linha" e o "do outro lado da linha”. Assim, para Santos (2010, p. 32):

A divisão é tal que o "outro lado da linha" desaparece enquanto realidade, torna-se inexistente, e é produzido como inexistente. Inexistência significa não existir sob qualquer forma de ser relevante ou compreensível. Tudo aquilo que é produzido como inexistente é excluído de forma radical porque permanece exterior ao universo que a própria concepção aceite de inclusão considera como sendo o Outro. A característica fundamental do pensamento abissal é a impossibilidade da copresença dos dois lados da linha. Este lado da linha só prevalece na medida em que esgota o campo da realidade relevante. Para além dela há apenas inexistência, invisibilidade e ausência não dialética.

Santos (2010) diz ainda que as diferenças visíveis que estruturam a realidade de um lado da linha baseiam-se na invisibilidade das diferenças entre um e outro lado. Daí que o binarismo metafórico visível/invisível usado para elaborar o conceito de pensamento abissal é fundado na impossibilidade de coexistência dos dois lados. Dentro da realidade visível, as diferenças seguem classificações, implacáveis construções de verticalidades hierárquicas que vão do mais claro, no topo, ao mais escuro, na base. Verticalidades com geometrias deterministas, ancoragens gráficas com evocações solares e hierarquias dégradés, percebidas, por exemplo, dentro do que Emmanuel Wallerstein (2004, p. 241) chama de sistema-mundo ${ }^{10}$, onde se estabilizam centros, semiperiferias e periferias utilizando, para tanto, uma lente eurocentrada. Abaixo da linha abissal, as opressões são agravadas pela racialização que dá ensejo justificado a várias formas de violência, exploração, expropriação e desumanização. Cria-se a ilusão, com ares de verdade, de que a luz é superior à escuridão, de que a luz é virtude e a inexistência de luz pura negatividade, de que o sol, portanto, é mais importante do que a lua. Propomos chamar essas ilusões, esses dispositivos (que produzem e estabilizam hierarquias e oposições) de "amarração". O termo não é escolhido por acaso, pois refere-se a uma das formas de se manter o navio atrelado ao cais de um determinado porto, uma forma 
de ancoragem, além do que é também usado para designar trabalhos de magia no Candomblé e na Umbanda (religiões de origem Iorubá), feitos por uma sacerdotisa ou sacerdote com a finalidade de estabelecer e fixar uma união amorosa. $\mathrm{O}$ ilusionismo moderno é constituído por trabalhos de amarração ego-geopolíticos, amarrações Terra-Sol. Ou seja, é solar, pois pressupõe um critério absoluto - a luz - e ainda uma única matriz irradiadora - o Sol - que precisa da Terra para operar sua geopolítica de colonização.

\section{Do pensamento abissal à colonialidade}

Tentando ir além da lógica única e determinista do pensamento hierárquico, o filósofo grego Kyriankos Kontopoulos (1993) elabora o termo "pensamento heterárquico". Para Santiago Castro-Gómes e Ramón Grosfoguel (2007, p. 18):

El pensamiento heterárquico es un intento por conceptualizar las estructuras sociales con un nuevo lenguaje que desborda el paradigma de la ciencia social eurocéntrica heredado desde el siglo XIX. El viejo lenguaje espara sistemas cerrados, pues tiene una lógica única que determina todo lo demás desde una sola jerarquía de poder. Por el contrario, necesitamos un lenguaje capaz de pensar los sistemas de poder como una serie de dispositivos heterónomos vinculados en red. Las heterarquías son estructuras complejas en las que no existe un nivel básico que gobierna sobre los demás, sino que todos los niveles ejercen algún grado de influencia mutua en diferentes aspectos particulares y atendiendo a coyunturas históricas específicas. En una heterarquía, la integración de los elementos disfuncionales al sistema jamás es completa, como en la jerarquía, sino parcial, lo cual significa que en el capitalismo global no hay lógicas autónomas ni tampoco una sola lógica determinante 'en última instancia' que gobierna sobre todas las demás, sino que más bien existen procesos complejos, heterogéneos y múltiples, con diferentes temporalidades, dentro de un solo sistema-mundo de larga duración. En el momento en que los múltiples dispositivos de poder son considerados como sistemas complejos vinculados en red, la idea de una lógica 'en última instancia' y del dominio autónomo de unos dispositivos sobre otros desaparece.

O pensamento abissal, moderno, ocidental, com pretensão de universalidade ${ }^{\mathrm{I}}$, foi construído e disseminado, como vimos, mediante dispositivos de dominação epistêmica. San- 
tos (2006, p. 137-165) busca contrapor a essa monocultura do conhecimento científico a ecologia de saberes, que é, a seu modo, outra forma de afirmar uma heterarquia epistêmica. Para Santos (2010, p. 53):

É uma ecologia, porque se baseia no reconhecimento da pluralidade de conhecimentos heterogêneos (sendo um deles a ciência moderna) e em interações sustentáveis e dinâmicas entre eles sem comprometer a sua autonomia. A ecologia de saberes baseia-se na ideia de que o conhecimento é interconhecimento.

A epistemologia dominante, monocultural, surge com a intervenção política, econômica e militar do colonialismo e se assenta na diferença cultural do mundo moderno cristão ocidental e na diferença política do capitalismo. O colonialismo reduziu a diversidade epistemológica e, mesmo após os processos de independência política, e até econômica, transmutou-se nisso que agora se chama "colonialidade". Antes mesmo de sua introdução como conceito, a ideia já se manifestava no pensamento africano de Kwame Nkhruma e Amilcar Cabral, principalmente; e negro nas Américas, como no de W.E.B. Dubois, Aimé Césaire, Frantz Fanon, Angela Davis, Sylvia Wynter, Abidias do Nascimento, Cedric Robinson, Édouard Glissant, Milton Santos; e também de feministas chicanas como Glória Evangelina Anzaldúa, Cherríe I. Moraga, entre outras.

Para chegar ao termo colonialidade, Aníbal Quijano (1992) argumenta que:

la idea de raza es, con toda seguridad, el más eficaz instrumento de dominación social inventado en los últimos 500 años. Producida en el mero comienzo de la formación de América y del capitalismo, en el tránsito del siglo XV al XVI, en las centurias siguientes fue impuesta sobre toda la población del planeta como parte de la dominación colonial de Europa.

Na síntese feita por Ramón Grosfoguel (2013a, p. 43), "la idea de 'colonialidad', es decir, que la raza es un principio organizador de la lógica de acumulación de capital, de la economía política y de la división del trabajo internacional del sistema capitalista mundial desde el siglo XVI". Grosfoguel (2013a, p. 44) diz ainda que "la 'colonialidad del poder' nace de la historia del colonialismo no es reductible a él porque una vez terminado el colonialismo la colonialidad ha continuado hasta nuestros días en todas sus manifestaciones". 
Para esses autores, a modernidade não pode ser concebida, e muito menos referida, sem imediatamente associá-la à colonialidade. Isso significa dizer que não é possível mencionar supostos avanços ou triunfos da modernidade ocidental sem que se ponha a nu o alto preço pago na colonialidade. Ambos, colonialidade e modernidade, são indissociáveis, uma vez que o segundo se constitui a partir do primeiro. Por isso, Walter Mignolo (2011) afirma que a colonialidade é o lado sombrio - the dark side ${ }^{12}$ - da modernidade. Mignolo (2007, p. 34) também escreve que:

[...] pone de manifiesto las experiencias y las ideas del mundo y de la historia de aquellos a quienes Fanon denominó les damnés de la terre ("los condenados de la tierra", que han sido obligados a adoptar los estándares de la modernidad). Los condenados se definen por la herida colonial, y la herida colonial, sea física o psicológica, es una consecuencia del racismo, el discurso hegemónico que pone en cuestión la humanidad de todos los que no pertenecen al mismo locus de enunciación (y a la misma geopolítica del conocimiento) de quienes crean los parámetros de clasificación y se otorgan a sí mismos el derecho a clasificar.

Nesta perspectiva, as hierarquias vistas na "panpolítica" da mitologia egípcia e grega foram substituídas pela "teopolítica” na Idade Média e, na modernidade, a teopolítica foi substituída pela "egopolítica". De acordo com Ramon Grosfoguel (2010, p. 460):

Descartes substitui Deus, fundamento do conhecimento na teopolítica do conhecimento da Europa da Idade Média, pelo Homem (ocidental), fundamento do conhecimento na Europa dos tempos modernos. Todos os atributos de Deus são agora extrapolados para o Homem (ocidental). Essa verdade universal que está para além do tempo e do espaço, o acesso privilegiado às leis do universo, e a capacidade de produzir conhecimento e teorias científicas, tudo isso está agora situado na mente do Homem ocidental.

Grosfoguel (2013b) diz ainda que "o ego-cogito cartesiano ('penso, logo existo') é o fundamento das ciências modernas ocidentais", e relembra os argumentos de Henrique Dussel na afirmação de que o "penso, logo existo" do século XVII foi precedido por 150 anos de "conquisto, logo existo" (ego-conquiro). Finalmente, conclui que, a partir de então, o que se vê na história da conquista da América é a aplicação do "extermino, logo 
existo" (ego-extermino), como fator de mediação sócio-histórica estrutural entre o ego-cogito e o ego-conquiro. É assim que os genocídios/epistemicídios do século XVI (ego-extermino) são fundantes das estruturas modernas de conhecimento.

Contudo, o pensamento filosófico que seculariza a teologia cristã hierarquizadora de mente (pensamento) e corpo, e que também subalterniza as localidades "outras", fora da Europa Ocidental ("o resto do mundo"), acaba por processar insensatez, desequilíbrios e injustiças percebidas, hoje em dia, em diversos problemas ambientais e sociais, além das irracionalidades da não coexistência.

A esse propósito, Donna Haraway (1988) afirma a necessidade de confrontar os conhecimentos em sua visada dualista, a qual lança uma cortina de fumaça sobre o corpo e a localidade, com a pretensão de fundar um universalismo abstrato não situado, em outras palavras, um universalismo onipresente. Assim, as amarrações platônicas, cartesianas, kantianas, hegelianas, recriam a representação, a magia, do Olho da Providência ${ }^{13}$, em uma perspectiva falconiana (que do alto observa a todos, mas não pode ser observado facilmente), e que lembra Re-Horakhty ${ }^{14}$, o deus da mitologia egípcia, e que ainda mantém uma perspectiva de "ponto zero". Segundo Santiago Castro-Gomez (2003 apud GROSFOGUEL, 2010, p. 460):

O "ponto zero" é o ponto de vista que se esconde e, escondendo-se, se coloca para lá de qualquer ponto de vista, ou seja, é o ponto de vista que se representa como não tendo um ponto de vista. É esta visão através do olhar de deus que esconde sempre a sua perspectiva local e concreta sob um universalismo abstrato. A filosofia ocidental privilegia a "egopolítica do conhecimento" em desfavor da "geopolítica do conhecimento" e do "corpo-política do conhecimento". Em termos históricos, isto permitiu ao homem ocidental (esta referência ao sexo masculino é usada intencionalmente) representar o seu conhecimento como o único capaz de alcançar uma consciência universal, bem como dispensar o conhecimento não ocidental por ser particularístico e, portanto, incapaz de alcançar a universalidade.

O iluminismo não só tira "teo" do centro político para nele colocar o homem, a saber, branco-europeu-judaico-cristão-capitalista-moderno, como também tenta fazer inúmeros trabalhos de amarração de tudo e de todos, a ego-política hegemônica que se assenta em um "castelo no céu"15. 
Figura 3

[Sem título] (2014), Daniel Pellegrim Sanchez

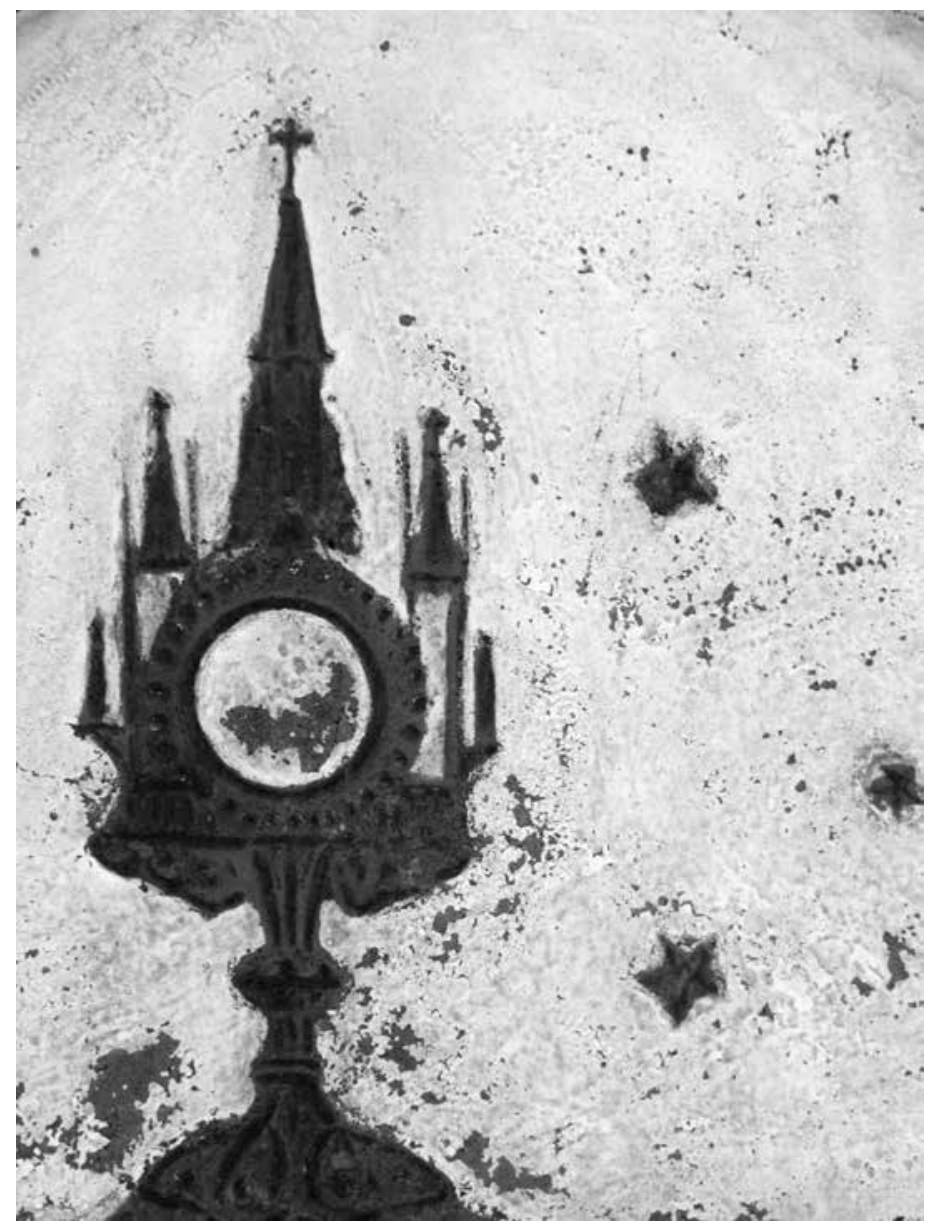

Explorar, sondar, controlar e dominar o universo a despeito dos outros que o compartilham revela-se arrogância comum ao pensamento moderno eurocentrado. O subsequente encobrimento do pensamento "outro", com classificações e hierarquizações, são os nós do mesmo pensamento. Se, por um lado, acumula e produz escassez, por outro, desclassifica-se, desqualifica-se, descredencia-se, gera insegurança e desconfiança em tudo aquilo que não está "amarrado".

A propósito do pensamento "outro", vale lembrar o esforço levado a efeito por Lévi-Strauss para descrever e classificar o suposto tipo de pensamento dos indígenas no Brasil, que, não tendo ciência nem arte, produziam ainda assim algum conhecimento. Nas comparações que faz entre as potencialidades dessas formas de conhecimento, destacando a primazia da 
ciência em sua capacidade especulativa, por ser fundada na abstração, o antropólogo propõe as expressões "pensamento selvagem", "pensamento do concreto", "pensamento mítico" e "bricolagem" para designar o modo de conhecimento e de pensamento em cuja descrição o antropólogo afirma tratar-se de um universo fechado, com dificuldades de incorporação do novo (particularidade do mito), incapacidade de abstração (particularidade do pensamento do concreto), criação limitada aos rearranjos com os mesmos elementos (característica da bricolagem), claramente em desvantagem aos modos ocidentais de pensar e conhecer (BRANDÃO; PRECIOSA, 2010). Esse pensamento, sabemos, dominou quase toda a Antropologia do século XX e alastrou-se pelas Humanidades, a qual se incumbiu de transformar a bricolagem lévi-straussiana, que designava uma suposta forma de pensamento dos indígenas, em modo operatório de "criação" (pleno de limitações) dos grupos subalternos em geral. Diante de um objeto único, não seriável, que impede a classificação como artesanato, utiliza-se a categoria "bricolagem".

Em entrevista, por ocasião da realização da exposição Estéticas Decoloniales (2010), na cidade de Bogotá, Walter Mignolo afirmou que a luta no século XXI, visando controle e poder, se faz através do controle do conhecimento. Nessa perspectiva, surge o problema da demarcação (contorno, fronteira) na filosofia da ciência, que diz respeito à dificuldade em fazer a distinção entre teorias científicas e teorias não científicas (que nem teriam o estatuto de teorias). A questão é o não reconhecimento da diversidade epistemológica, tanto no interior da ciência quanto na relação da ciência com outros conhecimentos/saberes não científicos.

A lógica da ciência moderna - do dividir para conhecer é responsável pelo estabelecimento de delimitações internas (ciências formais, ciências físico-químicas e experimentais, ciências sociais, ciências humanas etc.) e pela especialização do cientista, que é instado a dedicar-se a apenas uma dessas disciplinas, operando também, em seu interior, outras subdivisões.

Para Walter Mignolo (2010), as disciplinas acadêmicas são dispositivos de controle, uma vez que só se legitima o cientista que obedece às regras da disciplina, lógica essa que converte a ciência em uma gigantesca máquina de processar decadência epistêmica. Para esse autor, as narrativas de progresso científico, de salvação pela ciência, de sacralização da teoria, são formas de decadência epistêmica e disciplinar. Declínio que fica evidente através da persistência acrítica de noções e conceitos coloniais

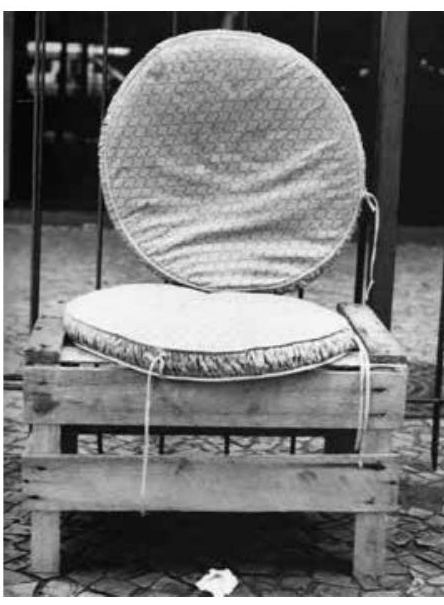

Figura 4

Caixote-poltrona. Fonte: PEREIRA, Gabriela de Gusmão. Rua dos Inventos, $2002^{16}$ 
racistas. Os domínios disciplinares estão relacionados, pela enunciação, com fundamentos patriarcais calcados na secularização da teologia cristã que se convertera, na Renascença, em filosofia e em ciência. Mignolo explica que a matriz colonial de poder atua em dois níveis: o do enunciado (o já realizado), o qual aparece diante de nossos sentidos através do discurso; e o da enunciação (ato de produzir o enunciado), onde se controla o conhecimento. Fica evidente a manipulação de enunciados e enunciações, desde o Iluminismo, que colocam a Europa como centro epistêmico do mundo, segundo uma ontologia diferenciadora que apaga aqueles que estão à margem. Para Mignolo, é preciso se desvincular das lógicas de domínio, onde a narrativa da inovação inferioriza conhecimentos tradicionais, locais etc., uma vez que se entrarmos em um conflito de disputa pelos domínios e não questionarmos os lugares e as regras dos lugares a partir dos quais esses domínios são constituídos, vigiados, controlados e mantidos viveremos sempre a angústia de uma suposta eterna e infinita defasagem, de um anacronismo atávico, que nos localiza sempre em alguma retaguarda.

Se o mundo julgou e ainda julga o Brasil como arcaico, agrário e patriarcal, o mesmo se reproduz também internamente, na relação que se estabelece entre os grandes centros urbanos e o interior do Brasil. Essa hierarquização urbana é cruzada com uma hierarquização de classe, gênero, etnia, entre as mais evidentes. Aos indígenas, negros e pobres em geral caberão as categorias desqualificadoras do pitoresco, exótico, selvagem, caipira. Palavras carregadas de preconceito e que expressam bem isso que Nelson Maldonado-Torres passou a chamar de "racismo epistêmico” (2008 apud BRANDÃO; GUIMARÃES, 2012).

\section{Abissalidades e colonialidades no mundo das artes}

É lugar comum atribuir ao suposto "isolamento" de cidades como as de nossas inserções - Cuiabá, capital de Mato Grosso e Chapada dos Guimarães a 6okm da capital - a razão para todos os igualmente supostos "atrasos" em relação aos critérios evolutivos ocidentais. A "civilização" aqui, diz-se, custou a chegar. Permanece no imaginário (e na ignorância) do sul-sudeste brasileiro que animais selvagens transitam por estas cidades, que o faroeste vigora neste espaço designado "de fronteira". Se o estereótipo tivesse fundamento, estas cidades caracterizadas por suas centralidades geodésicas da América do Sul, equidistantes, portanto, dos oceanos Pacífico e Atlântico -lóci iniciais 
dos processos de colonização na América do Sul - poderiam estar a salvo, talvez, da integralização do processo colonizador e das subsequentes formas atuais da colonialidade. No caso das artes, poderíamos nem ter "arte", nos termos ocidentais. Mas não é exatamente o que aqui acontece.

Nesta última década, ambos os autores deste artigo atuaram - um como artista e produtor cultural, outra no âmbito da crítica, das atividades curatoriais e da pesquisa acadêmica - no que se pode chamar de circuito artístico do Estado de Mato Grosso e, mais especialmente, de sua capital Cuiabá e zona de influência.

Por meio da Pellegrim Galeria de Arte ${ }^{17}$, acompanhamos a carreira de 20 artistas, participamos de editais públicos de incentivo à cultura, frequentamos ateliês, produzimos exposições e, mesmo em um âmbito restrito (Mato Grosso), pudemos vivenciar as contradições, tensões e angústias desse meio artístico.

Na crítica de arte e na academia, por sua vez, o primeiro enfrentamento que tivemos é com a "regionalização" da arte que aqui se faz. É de longa data a discussão nacional/regional no âmbito da pesquisa histórica e da literatura que se ressentem, com razão, de terem seus produtos sempre caracterizados como regionais enquanto a produção do eixo Rio-São Paulo (a nossa Europa) dispensa predicações, ou seja, são história do Brasil e literatura brasileira. Assim como a história não é do Brasil e a literatura não é brasileira, as artes aqui são igualmente carimbadas de "regionais". Na impossibilidade de confrontar o predicado/estigma, aceitam-se designações como arte ingênua, naïf, popular ou, na tentativa de não deixar-se sobrecodificar, inventa-se outras como arte "cabocla"18.

A predicação não é inofensiva. Ao contrário, sob a capa de uma "boa vontade" do circuito oficial de artes (críticos, pesquisadores, galerias, artistas renomados, imprensa etc.) que aceita incluir sob o manto das artes essas produções diferenciadas, opera-se uma desqualificação definitiva.

Em "Desconstruindo o naï: a pintura de Alcides dos Santos" (BRANDÃO; GUIMARÃES, 2012), procuramos demonstrar como funcionam essas adjetivações, como elas caracterizam extrinsecamente o trabalho artístico, dizendo exclusivamente sobre as origens do criador (se é indígena, popular, rústico etc.) e omitindo uma crítica verdadeira às obras, às suas características composicionais, como se dá com os artistas e obras do circuito "nacional".

No embate dos editais para pesquisa e curadoria, na área das artes visuais, essa predicação/desqualificação pesa sobre o corpus artístico dito "regional", uma vez que lhe é negada, de 
partida, a relevância nacional e, muito menos, internacional, o que tem justificado algumas negativas às nossas submissões ${ }^{19}$.

Antes de compreendermos do que se tratava enfim essas experiências, em nossas atuações, na percepção das dificuldades de legitimação para a necessária autonomização (BOURDIEU, 1999) do sistema de arte em Mato Grosso, entendíamos que os problemas eram de ordem prática ou que os problemas eram, evidentemente, nossos e de nossa região.

Estudando o mercado de artes visuais mundial, identificamos o funcionamento articulado de um sistema que conta com grandes instituições promotoras, galerias, revistas, coleções, eventos de variadas escalas, e constamos que sua organização, de maneira geral, parecia seguir uma escala geográfica, onde os artistas que acompanhávamos (todos "regionais"), para conseguirem autonomia e legitimação em âmbito estadual, teriam que "conquistar" Cuiabá; em âmbito regional, Brasília; em nível nacional Rio de Janeiro e São Paulo; em nível mundial, Nova York e Paris.

$\mathrm{Na}$ atividade de pesquisa, salvo exceções, a conquista de financiamentos para projetos de investigação sobre esses artistas depende igualmente dessa "conquista de legitimidade", cuja visibilidade curiosamente lhe precede, forjando uma estranha lógica (quase um paradoxo) em que para ser objeto de pesquisa, o artista e sua obra precisam ser previamente conhecidos e valorizados.

Mais do que nós pesquisadores, críticos e promotores culturais, os artistas, além de enfrentarem cotidianamente essa geopolítica das artes, também confrontam-se com os determinismos da hierarquia epistêmica e biológica. Não raramente nos defrontávamos com situações de preconceito e exploração. É aqui que verificamos que o suposto "isolamento" não nos salvou da colonialidade. Mesmo nesta realidade dita "mais profunda do país", encontramos reproduzidas, e se reproduzindo, as mesmas perversidades da colonialidade e, o que é pior, verificamos que não há perspectiva nenhuma de que o artista destas plagas, mesmo passando a radicar geograficamente em um centro, em uma metrópole, venha a conseguir autonomia ou legitimação, uma vez que o espaço que lhe será conferido será sempre aquele das periferias das metrópoles.

Com Quijano (1992), vimos que este dégradé hierárquico não se reduz tão somente aos aspectos geográficos ou mesmo econômicos, estas hierarquias são construídas também, e principalmente, pela produção de distinções biológicas como raça, sexualidade, saúde etc. Pessoas racializadas, patologizadas são subalternizadas tanto nas metrópoles, como no interior. 
Enfim, demonizar o escuro, hadonizar ${ }^{20} \mathrm{o}$ interior, ocultar a lua, calar, emular através de uma competitividade de massacre são artifícios de homens que representam, que têm a denotação como estratégia política. Evocar o sol, o olho celestial, representar Deus e se amarrar em geometrias deterministas, faz parte do fundamentalismo ego-político que segue atravessando corações, mentes e instituições, inclusive as que se dedicam ao suposto cultivo do espírito, como as artísticas e acadêmicas.

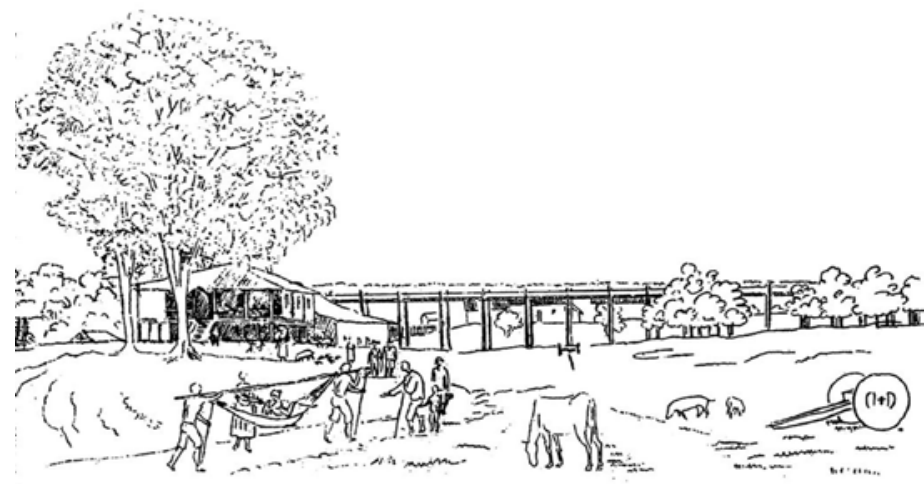

Ao vermos a imagem acima, do engenho do Buriti em Chapada dos Guimarães, onde aparecem escravos carregando o patrão em uma rede, nos damos conta de que seguimos sendo os carregadores da rede em outro regime certamente, e nela, seguem sendo carregados os valores e os saberes do topo da hierarquia. Não se trata, portanto, de trocar carregados e carregadores. Mais uma vez, uma palavra muito usada nos ritos do candomblé e da umbanda vem ao nosso auxílio: descarrego. Entre outros significados encontra-se o de "livrar-se do peso". Neste caso, soltar a rede com tudo o que nela vai! Embora a ideia de tombo nos incite a uma rebeldia irônica à brasileira, talvez uma traquinagem circense, pensamos em soltar a rede não como um ato de contumaz de violência, de provocar um acidente que possa machucar "o patrão", mas tão somente como a opção de não mais carregá-lo. O peso desse indivíduo - macho, branco, cristão, ocidental, capitalista, moderno - e suas tralhas tensionam de tal maneira os punhos e os fios nele arrematados, que se torna praticamente impossível desfazer os nós das amarrações. O privilégio de ser carregado em uma horizontalidade acima da terra, de estar flutuando como em um castelo no céu, não só
Figura 5

Reprodução do desenho do Engenho do Buriti, feito por Hércules Florence, durante a Expedição Langsdorff, no século XIX, exposto na Sala da Memória em Chapada dos Guimarães - MT. Fotografia: Daniel Pellegrim Sanchez 
sustenta a "verticalidade do dégradé hierárquico", como também mantém a pressão sobre as linhas da rede. Ao soltar-se de uma rede que explora, escraviza, ou causa infelicidade, teremos tempo para tecer redes outras, mais dignas e autossustentáveis. Soltá-la, desfazer os nós com uma alavanca newtoniana, se for preciso, redefinir seu uso com logos outros é o que nos resta e compete fazer mais do que nunca.

NOTAS

1. "Palhaço do Circo sem Futuro" é o título do disco (2002) do grupo Cordel do Fogo Encantado. Grupo lítero-musical de Arcoverde, Pernambuco.

2. Fossas abissais são as regiões mais profundas dos oceanos. Depressões que se formam abaixo do talude continental, em zonas de encontro de placas tectônicas, onde uma placa mergulha sobre a outra (UNIVERSIDADE LUSÓFONA).

3. O autor consta como referência em um ficheiro da WIKIPÉDIA (2013).

4. Nessas condições, os seres vivos possuem corpos gelatinosos que lhes permitem suportar a grande pressão, têm movimentos lentos e resistem longos períodos de tempo sem alimento (ARAGUAIA, Maria).

5. Segundo Machado (2007), a semiosfera, conceito formulado pelo semioticista russo Iuri Lotman, designa o espaço da cultura que funciona como um organismo no qual não se separam aspectos biológicos e aspectos culturais. Trata-se de um espaço, ao modo da biosfera, que possibilita a realização dos processos comunicativos e da produção de novas informações, resultando um conjunto de diferentes textos e linguagens.

6. Veja BBC BRASIL.

7. A abissofobia é um medo incomum que o indivíduo tem de abismos e de precipícios (ABC DE FOBIAS).

8. Troposfera é a porção mais baixa da atmosfera terrestre onde o ser humano respira.

9. A espécie é encontrada em todos os oceanos numa profundidade entre 100 e 2 mil metros (SPIEGEL ONLINE, 2010).

10. Para Emmanuel Wallerstein (2004, p. 241) trata-se de um regime global de poder que tem como característica uma "superestrutura política que consiste em um conjunto de Estados supostamente soberanos definidos e limitados por seu pertencimento a uma rede ou sistema interestatal, cujo funcionamento se guia pelo chamado equilíbrio de poder, mecanismo destinado a garantir que nenhum dos Estados que formam parte deste sistema interestatal tenha nunca a capacidade de transformá-lo em um império-mundo".

11. A pretensão de universalizar o pensamento ocidental está posta, por exemplo, no idealismo absoluto do filósofo alemão Georg Wilhelm Friedrich Hegel.

12. Um dos livros de Mignolo traz exatamente o título The darker side of the renaissance.

13. O olho de Deus que observa a humanidade.

14. Hibrido de Rá (Deus Sol na mitologia egípcia) e Hórus (dos Dois Hori- 
zontes) que, segundo essa mitologia, era o soberano de todas as partes do mundo, ou seja, do céu, da terra e do mundo inferior.

15. Título do filme de animação de Hayao Miyazaki, 1986.

16. Esse objeto "de rua" exemplifica o que queremos dizer com a classificação apressada e equivocada de bricolagem para invenções populares.

17. A Pellegrim Galeria de Arte resultou de um curso de Especialização em Planejamento e Gestão Cultural. O espaço funcionou de 2003 a 2009 e realizou mais de vinte exposições apresentando artistas do estado de Mato Grosso, em sua maioria de Cuiabá. A escolha de Chapada dos Guimarães se deu em função do fluxo turístico sistemático da cidade.

18. Aline Figueiredo, crítica de arte e animadora cultural da maior importância no Estado e para sua produção visual, desde os anos 70, cunhou a arte aqui produzida pela chamada segunda geração dos artistas formados no âmbito do Ateliê Livre da UFMT, de "cabocla”. A designação não somente foi acolhida como foi repercutida por críticos de renome nacional e internacional.

19. É preciso fazer justiça à CAPES que concedeu a primeira importante aprovação a um projeto de pesquisa em Artes Visuais na UFMT, mediante Edital P̧NPD Institucional 2011 e que colocou duas bolsistas pós-doc para atuar no projeto sob coordenação de Ludmila Brandão.

20. De Hades, o deus grego da morte e do mundo inferior (HESÍODO, 2012, p. 127 e 147).

\section{Referências}

BRANDÃO, Ludmila; GUIMARÃES, Suzana. Desconstruindo o naif: a pintura de Alcides dos Santos. Revista Contrapontos. Santa Catarina: Univali. Vol. 12 n3, p. 308-316, set-dez, 2012.

BRANDÃO, Ludmila; PRECIOSA, Rosane. A invenção e a rua: da apropriação/reinvenção de objetos precários. Concinnitas 17, ano 11, v. 2. Dezembro de 2010, 148-159.

BOURDIEU, Pierre. A economia das trocas simbólicas. São Paulo: Perspectiva, 1999.

CASTRO-GÓMEZ, Santiago; GROSFOGUEL, Ramón (Org.). El giro decolonial: reflexiones para una diversidad epistémica más allá del capitalismo global. Bogotá: Siglo del Hombre .; Universidad Central, Instituto de Estudios Sociales Contemporáneos y Pontifícia Universidad Javeriana, Instituto Pensar, 2007.

GROSFOGUEL, Ramon. Para descolonizar os estudos de economia política e os estudos pós-coloniais: transmodernidade, pensamento de fronteira e colonialidade global. In: SANTOS, Boaventura de Sousa. MENESES, Maria Paula (Org.). Epistemologias do Sul. São Paulo: Cortez, 2010.

. Hay que tomarse en serio el pensamiento crítico de los colonizados en toda sua complejidade. Entrevista realizada por Luis Martínez Andrade, Metapolítica, ano 17, núm. 83, octubre - diciembre de 2013 a. 
. Racismo/sexismo epistémico, universidades occidentalizadas y los cuatro genocidios/epistemicídios del largo siglo XVI. Tábula Rasa. Bogotá - Colômbia, No. 19: 31-58, julio-diciembre $2013 \mathrm{~b}$.

HARAWAY, Donna. Situated Knowledges: the Science Question in Feminism and the Privilege of Partial Perspective. Feminist Studies, 1988.

HESIODO. Teogonia: a origem dos deuses. 2. ed. Estudo e tradução Jaa Torrano. São Paulo: Iluminuras, 2012.

QUIJANO, Aníbal. "Raza”, "Etnia”, "Nación”, Cuestiones Abiertas. In: Roland Forgues, ed. José Carlos Mariategui y Europa. La otra cara deldescubrimiento. Lima: Ed. Amauta, 1992.

KONTOPOULOS, Kyriankos.The Logic of Social Structures. Cambridge: Cambridge University Press, 1993.

MACHADO, Irene. (Org.). Semiótica da Cultura e Semiosfera. São Paulo: Annablume/Fapesp, 2007.

MIGNOLO, Walter D. La Idea de América Latina: La herida colonial e la opción decolonial. Barcelona: Editorial Gedise S.A., 2007.

.The darker side of western modernity. Global Futures, Decolonial Options. Duke University Press, Durham \& London, 2011.

.Decolonial Aiesthesis and Other Options Related tho Aesthetics. Be.Bop 2012. Black Europe Body Politcs. Berlin. Alemanha, 2012.

PEREIRA, Gabriela de Gusmão. Rua dos inventos: ensaio sobre desenho vernacular. Rio de Janeiro: Ed. Francisco Alves, 2002.

SANTOS, Boaventura de Sousa; MENESES, Maria Paula (Org.). Epistemologias do Sul. São Paulo: Cortez, 2010.

Para uma sociologia das ausências e uma sociologia das emergências. In: BARREIRA, César (Ed.). Sociologia e Conhecimento além das Fronteiras. Porto Alegre: Tomo Editorial, 2006.

. Toward a New Common Sense: law, science and politics in the paradigmatic transition. Nova Iorque: Routledge, 1995 .

WALLERSTEIN, Emmanuel. Capitalismo histórico y movimentos antisistémicos: Un análisis de sistemas-mundo. Barcelona: AKAL; 2004.

\section{Sites}

ABC DE FOBIAS. Lista de fobias. Disponível em: <http://abcdefobias.blogspot.com.br/2009/o2/abissofobia.html>. Acesso em: 24 jul. 2013. 
ARAGUAIA, Maria. Seres da zona abissal. Disponível em: $<$ http://www.brasilescola.com/biologia/seres-zona-abissal. htm>. Acesso em: 22 jul. 2013.

BBC BRASIL. Tiefsee. Disponível em: <http://jie.itaipu.gov.br/ print_node.php?secao=turbinadası\&nid=9391 $>$. Acesso em: 23 jul. 2013.

MIGNOLO, Walter. Estéticas Decoloniales. 2010, Disponível em: < https://www.youtube.com/watch?v=mqtqtRj5vDA $>$. Acesso em: 20 maio 2013.

SPIEGEL ONLINE, 2010. Disponível em: <http://www.spiegel.de/fotostrecke/tiefsee-ausstellung-bizarre-wesen-aus-den-tiefen-der-ozeane-fotostrecke-61475-6.html>. Acesso em: 24 fev. 2014.

UNIVERSIDADE LUSÓFONA. Classificação dos Ambientes Marinhos. Disponível em: <http://oficinaexperimental.wikispaces. com/file/view/classificacao_ambientes_marinhos.pdfs. Acesso em: 20 jul. 2013.

WIKIPÉDIA, 2013.Pelagiczone. Disponívelem:<http://pt.wikipedia. org/wiki/Ficheiro:Pelagiczone_pt.svg>. Acesso em: 24 fev.2013.

Recebido em: 05/01/15

Aceito em: 21/03/15

\section{DANIEL PELLEGRIM SANCHEZ}

s15atelie@gmail.com

Artista, Mestrando em Estudos de Cultura Contemporânea da Universidade Federal de Mato Grosso (UFMT), Especialista em Planejamento e Gestão Cultural pela Universidade de Cuiabá (UNIC/ PUCMG), Bacharel em Direito na Universidade de Cuiabá (UNIC).

\section{LUDMILA DE LIMA BRANDÃO}

ludbran@terra.com.br

Doutora em Comunicação e Semiótica pela Pontifícia Universidade Católica de São Paulo (PUC-SP), pós-doutorado em Crítica da Cultura pela Université d'Ottawa/Canadá. Coordenadora de Ensino de Pós-Graduação da UFMT e do Núcleo de Estudos do Contemporâneo (CNPq/UFMT). 